\title{
KEMAPANAN DIALEK TAMIM
}

Imroatul Fatihah

IAIN Syekh Nurjati Cirebon

Email: iimfatihah@gmail.com

\begin{abstract}
Abstrak
Penelitian sederhana ini berkesimpulan akan kemapanan dialek Tamim. Kemamapan dialek Tamim bersdasarkan pertumbuhan dialek-dialek yang ada yakni, secara sosiologis dan geografis. Secara sosiologis, dialek Tamim tidak dapat tidak bercampur dengan dialek-dialek tetangganya yang menyebabkan saling pengaruh dan mempengaruhi diantara mereka. Secara geografis, dialek Tamim memiliki tempat dimana ia tinggal dan berkembang, apalagi qabilah Tamim juga sering melakukan hijrah dalam mempertahankan hidupnya sehingga memperluas wilayah yang disinggahinya.
\end{abstract}

Kata Kunci: Dialek, Dialek Tamim, Quraisy, Arab

\section{Abstract}

This simple research concludes the establishment of the Tamim dialect. Tamim's dialect fortune is based on the growth of existing dialects, sociologically and geographically. Sociologically, the Tamim dialect cannot be mixed with neighboring dialects which cause mutual influence and influence between them. Geographically, the Tamim dialect has a place where it lives and develops, moreover Tamim also often migrates in defense of his life so as to expand the area he visited.

Keywords: Dialect, Tamim Dialect, Quraysh, Arabic

\section{Pendahuluan}

Para ilmuan dan cendekiawan sepakat bahwa bahasa Arab merupakan bahasa yang paling lama digunakan dan lebih awal munculnya, dan ia tergolong bahasa semit (samiyah) yang lebih maju, lebih lengkap dan lebih dekat dengan bahasa ibu dengan bahasa-bahasa yang satu asal dengannya yaitu Suryaniyah, Asyuriah, Habasyiyah dan Babiloniah. ${ }^{1}$

Bahasa Arab juga diakui sebagai bahasa terkaya dia antara bahsabahasa lain di muka bumi. Oleh karenanya, kajian terhadap bahasa Arab akan selalu "baru", meskipun tidak sedikit yang mengatakan bahwa kajian terhadap bahasa ini masih miskin, apalagi kajian terhadap dialek-

${ }^{1}$ Anwar al Jundi, Muqaddimat al 'Ulum wa al Manahij; Muhawalah libina'i Manhajin Islamiyyin Mutakamil, jilid: 4. (Kairo: Dar al Anshar). Hal. 5. 
dialek bahasa ini diakui masih baru dan jarang. ${ }^{2}$ Dialek-dialek Arab amat beragam antara lain: Quraisy, Hudzail,, ${ }^{3}$ Hijaz, Najd, Qais, Asad, Anshar, Aliyah, Rabi'ah, Mudhar, Yaman, Thay', Kananah, Hamir, Kalb, Hawazin, Uqail, Salim, Kahlan, ${ }^{4}$ Arab Utara, ${ }^{5}$ Mesir, Sudan, Yaman dan Arab Saudi. ${ }^{6}$

Dalam makalah yang sederhana ini, penulis tidak membahas seluruh dialek-dialek tersebut di atas melainkan penulis mencoba membahas dialek Tamim sebagai bagian dari Arabiyyah Baqiyah yang dianggap nomaden dan memiliki sedikit peradaban dibanding dengan Quraisy. Meskipun dialek Tamim berada pada level kedua dalam kehidupan sosial masyarakat Arab, dialek ini tidak tergerus penggunaannya dalam masyarakat Arab dengan dialek yang berada pada level pertama. Makalah ini mencoba menjawab masalah tersebut.

\section{Asal Dialek Tamim dan Wilayah Penyebarannya}

Bangsa Arab memiliki beberapa tingkatan keturunan (nasab), yaitu: Sya'b, Qabilah, 'Amarah, Bathn, Fakhdz dan Fashilah. Sya'b menempati urutan pertama sedang qabilah menempati urutan kedua dan begitu seterusnya sampai fashilah. Jadi, dalam sya'b terdiri dari beberapa qabilah, dalam qabilah terdiri dari beberapa 'amarah, dalam 'amarah terdiri dari beberapa bathn, dalam bathn terdiri dari beberapa fakhdz dan dalam fakhdz terdiri dari beberapa fashilah. ${ }^{7}$

Dalam kehidupan kemasyarakatan masyarakat Arab, sekurangkurangnya ada dua tingkatan. Pertama, qabilah-qabilah yang memiliki peradaban, potensi, kemampuan material, dan sastra yang tinggi. Kedua, qabilah-qabilah dengan kehidupan nomaden dan sedikit peradaban. ${ }^{8}$

2 Abd al Rahman Ayyub, Al Arabiyyah wa Lahjatuha. (Kairo: Maktabah Syabab). Hal. 1.

${ }^{3}$ Ibn Hajar al 'Asqalani, Fath al Bari, ix: 9.

${ }^{4}$ Lihat Daud Salum, Dirasah al Lahjat al Arabiyyah al Qadimah. (Beirut: Alam al Kutub, 1406/1986). Hal. 33-75.

${ }^{5}$ Abd al Ghaffar Hamid Hilal, Al Lahjat al Arabiyyah; Nasyatan wa Tathawwuran. (Kairo: Maktabah Wahbah, 1414/1993). Hal. 34.

${ }^{6}$ Abd al Rahman Ayyub, Al Arabiyyah wa Lahjatuha. (Kairo: Maktabah Syabab). Hal. 43-44.

7 Abu al Abbas Ahmad bin Ali, Fuqlaid al Juman fi Ta'rif bi qabail Arab al Zaman. (Kairo: Dar al Kutub al Islamiyyah, 1982). Hal. 14-15.

${ }^{8}$ Abd al Shabur Syahin, Fi Ilm Lughah al 'Am. (Beirut: Muassasah al Risalah, 1996). Hal. 221-222. 
Untuk tingkatan pertama, wilayah tempat mereka untuk bertinggal adalah kota-kota besar seperti, Mekah, Yatsrib atau Madinah, kota-kota di Yaman, Syam dan Irak yang berdekatan dan bercampur dengan bangsa-bangsa Persia dan Romawi, terutama qabilah yang tinggal di bagian utara dan barat seperti, qabilah Quraisy, Hudzail, Tsaqif, Aus dan Khadraj. Sedang untuk tinggkatan kedua, mereka sering dan selalu berpindah-pindah dalam mencari tempat tinggal dan rasa aman. Qabilah-qabilah ini lebih dominant di bagian timur dan tengah Jazirah Arabia seperti, Tamim, Qais dan Asad. ${ }^{9}$

Meskipun Tamim berada pada level kedua dalam kehidupan sosial masyarakat Arab akan tetapi ia tidak dapat dikesampingkan atau dipandang sebelah mata. Karena Tamim, sebagai level kedua dalam kehidupan sosial masyarakat Arab, merupakan qabilah yang memiliki komunitas yang besar dan tersebar di Jazirah Arabia.

Dialek Tamim merupakan bagian dari bahasa Arab al Baqiyah yaitu bahasa Arab yang masih dikenal dan digunakan hingga saat ini, baik dalam bentuk tulisan, karangan atau sastra. Adapun bahasa Arab al Baidah merupakan bahasa Arab yang dikenal berita akan pernah digunakannya bahasa tersebut namun tidak lagi digunakan saat ini. ${ }^{10}$

Jika ditarik kebelakang, maka bahasa Tamim berada pada Arab bagian Utara sedang bahasa Arab bagian Selatan terdiri dari Mu'iniyah, Sabaiyah, Hadhramiyah, Qatbaniyah dan Habasyiyah. Dan jika ditarik kebelakang lagi, maka bahasa Tamim berpangkal pada bahasa induk semit (samiyah) bagian Barat, dimana bahasa induk Semit terbagi menjdai dua bagian, bagian Timur dan bagian Barat. Bagian Timur meliputi bahasa Babiliyah dan Asyuriyah sedang bagian Barat meliputi bahasa Aramiyah, Kan'aniyah dan Arabiyah. ${ }^{11}$

${ }^{9}$ Abd al Shabur Syahin, Fi Ilm Lughah al 'Am. (Beirut: Muassasah al Risalah, 1996). Hal. 221-222.

${ }^{10}$ Abd al Rahman Ayyub, Al Arabiyyah wa Lahjatuha. (Kairo: Maktabah Syabab). Hal. 39.

11 Amil Badi' Ya'qub, Figh al Lughah al Arabiyyah wa Khashaishuha. (Beirut: Dar al Tsaqafah al Islamiyyah). Hal. 113-114.

El-Ibtikar Vol 7 No 1 Juni 2018, 109-121 
Bagan asal usul bahasa Arab:12

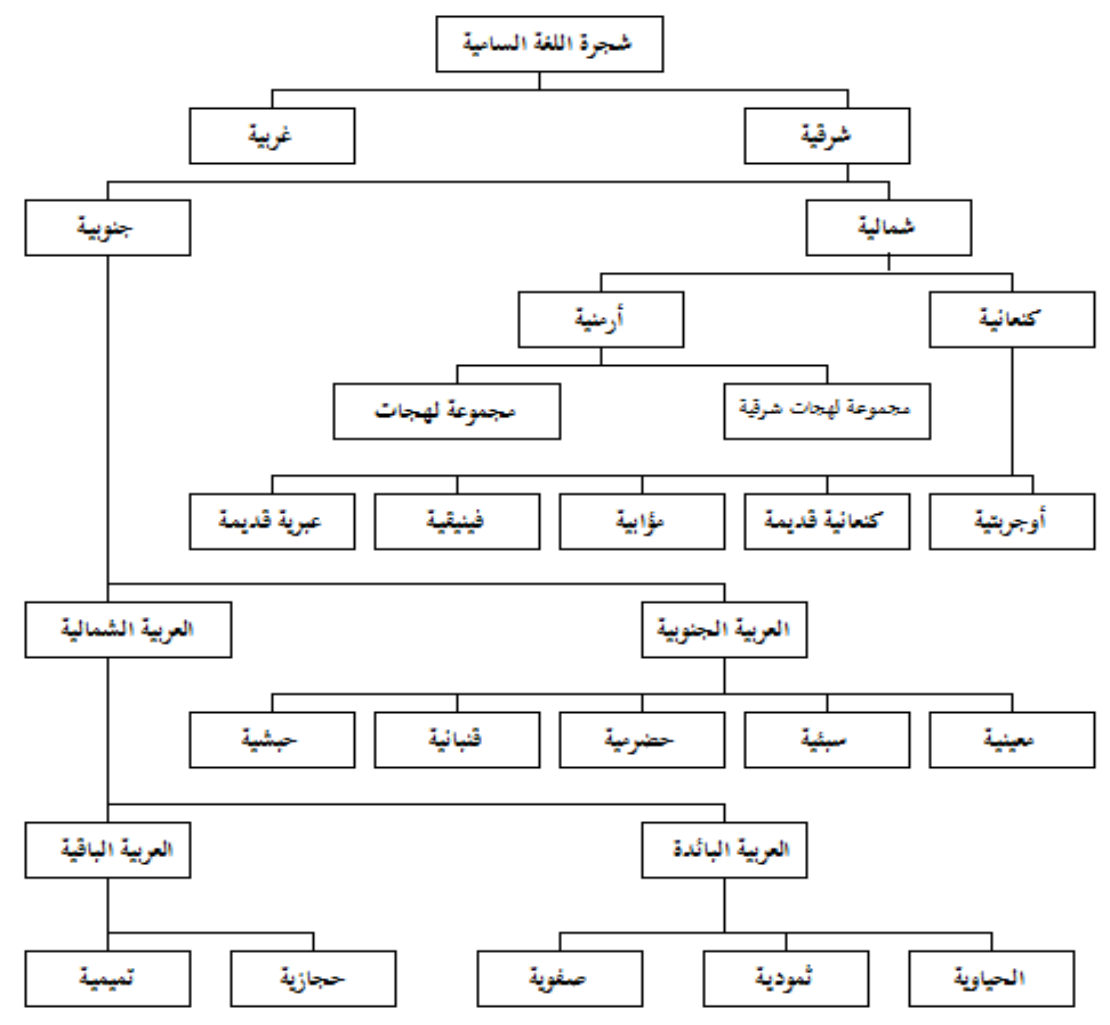

Bani Tamim merupakan qabilah besar dari Adnaniyyah yakni nasabnya bersambung sampai Adnan. Adapun nenek moyang mereka adalah Tamim bin Murrah bin Add bin Thabikhah bin Ilyas bin Mudharr bin Nazar bin Mu'id bin Adnan. ${ }^{13}$

Sedang wilayah penyebaran dialek ini antara lain Bahrain, Amman, Bashrah, Aliyah, Syam ${ }^{14}$ dan Irak. ${ }^{15}$

${ }^{12}$ Taufiq Syahin, 'Awamil Tanmiyah al Lughah al 'Arabiyyah. (Kairo: Maktabah Wahbah, 1980). Hal. 43.

${ }^{13}$ Muhammad As'ad al Nadiri, Figh al Lughah wa Masailuhu. (Beirut: al Maktabah al Ashriyah, 2005). Hal. 159.

${ }^{14}$ Daud Salum, Dirasah al Lahjat al Arabiyyah al Qadimah. (Beirut: Alam al Kutub, 1406/1986). Hal. 11-14.

${ }^{15}$ Daud Salum, Dirasah al Lahjat al Arabiyyah al Qadimah. (Beirut: Alam al Kutub, 1406/1986). Hal. 145. 
Bagan Arab Musta' ribah, ${ }^{16}$

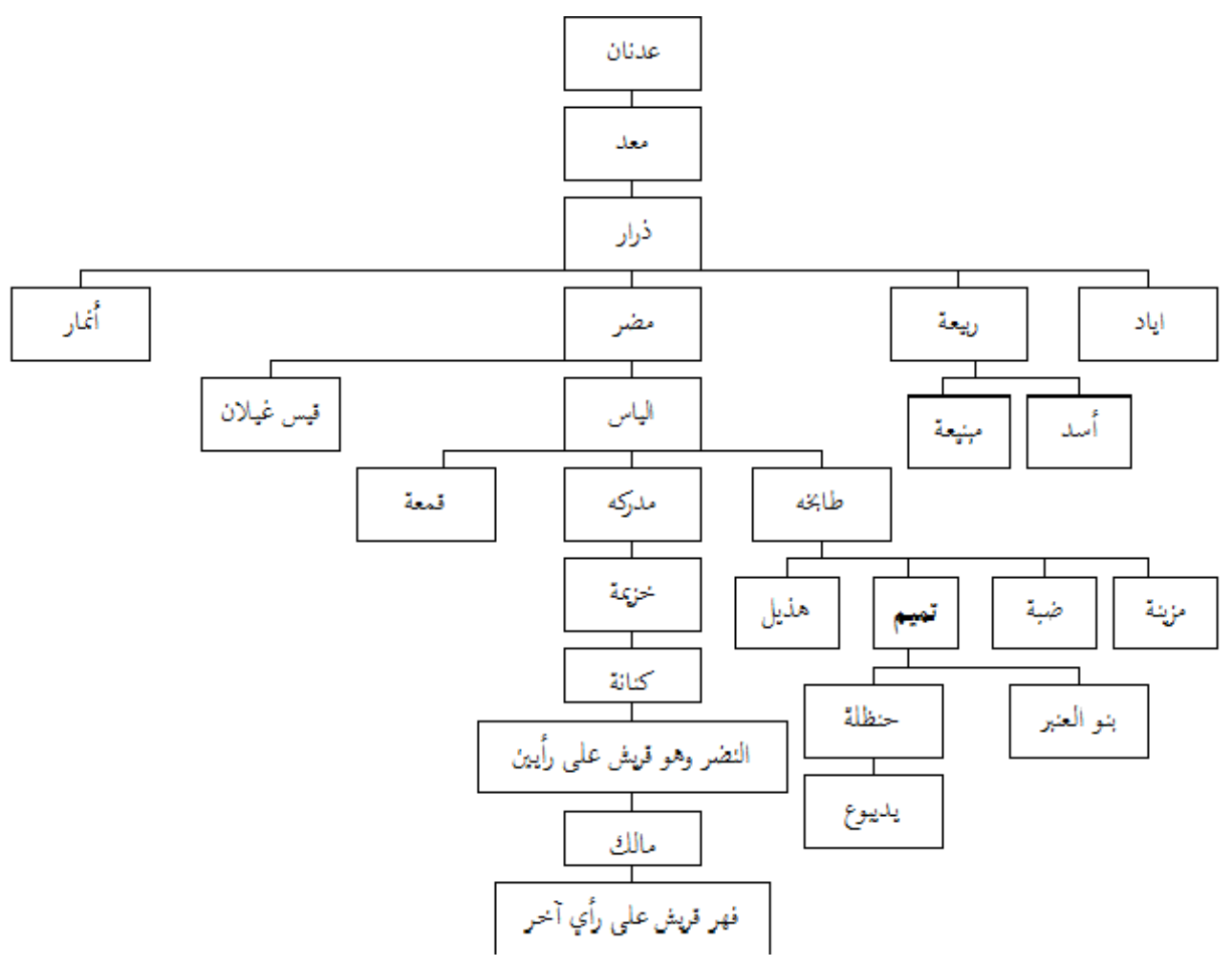

\section{Contoh-Contoh Dialek Tamim}

\section{a. Fi'l Madhi}

Al Ta'addiyah:

\begin{tabular}{|c|c|}
\hline Dialek Tamim & Dialek Non-Tamim \\
\hline 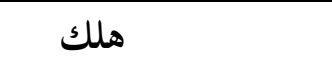 & أهلك \\
\hline هدى & 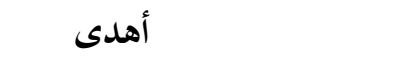 \\
\hline تعذر - تعذُّرُ & اعتذر - اعنذار \\
\hline 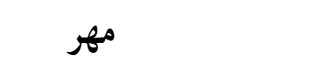 & أمهر \\
\hline أجزأ أ & جزى \\
\hline أحقق & حقق \\
\hline أفتأ & فتئ / فتأ \\
\hline
\end{tabular}

${ }^{16}$ Ahmad al Iskandari dan Mushthofa 'Anani, Al Wasith fi al adab al 'Arabi wa Tarikhihi, jilid I. (Gontor: Darussalam Press). Hal. 6-9. 


\begin{tabular}{|c|c|}
\hline افنتت & فنتت \\
\hline أهديت & هديت \\
\hline أسلك & سلك \\
\hline أرجع & رجع \\
\hline أمضى & مضى \\
\hline أحزن17 & حزن \\
\hline
\end{tabular}

Huruf, harokat dan sejenisnya:

\begin{tabular}{|c|c|}
\hline Dialek Tamim & Dialek Non-Tamim \\
\hline أَمْلَيْتُ - أُمْلِلى & أَ أَمْلَتْت - أملُ \\
\hline 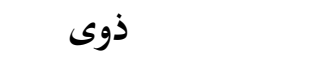 & ذأى \\
\hline استَحَى & استحيى \\
\hline فاظَت & فاضت \\
\hline ضِلِلْتُ & ضَتَلَتُتُ \\
\hline مِخِضْت & مَخَضْتْ \\
\hline 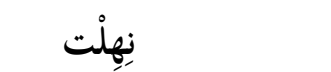 & نَهَهْلت \\
\hline سِخِرْت 18 & سَخَرْت \\
\hline
\end{tabular}

\section{b. Fi'1 Mudhari'}

\begin{tabular}{|c|c|}
\hline Dialek Tamim & Dialek Non-Tamim \\
\hline فَرَغَ - يَفْرغُ & فَغَغَغ - يَفْرُ غُ \\
\hline رَضِعَ - يَرْضَعُعُ & رَضَعَ - يَرْضِعُعُ \\
\hline حَالَ - يَحَالُ & حَوَلَ - يَحْوَلُ \\
\hline يُعَلِّمْهُم & يُعَلَّمُهُمْ \\
\hline 19 يَلْعَنْهُم & يَلْعَنُهُم \\
\hline نِقرأ & نَقَرأ \\
\hline
\end{tabular}

17 Ibrahim Anis, Fi al Lahjat al Arabiyyah. (Kairo: Maktabah al Anjalu al Mishriyyah, 1973). Hal. 160.

${ }^{18}$ Daud Salum, Dirasah al Lahjat al Arabiyyah al Qadimah. (Beirut: Alam al Kutub, 1406/1986). Hal. 64-65.

19 Abd al Ghaffar Hamid Hilal, Al Lahjat al Arabiyyah; Nasyatan wa Tathawwuran. (Kairo: Maktabah Wahbah, 1414/1993). Hal. 300-303. 


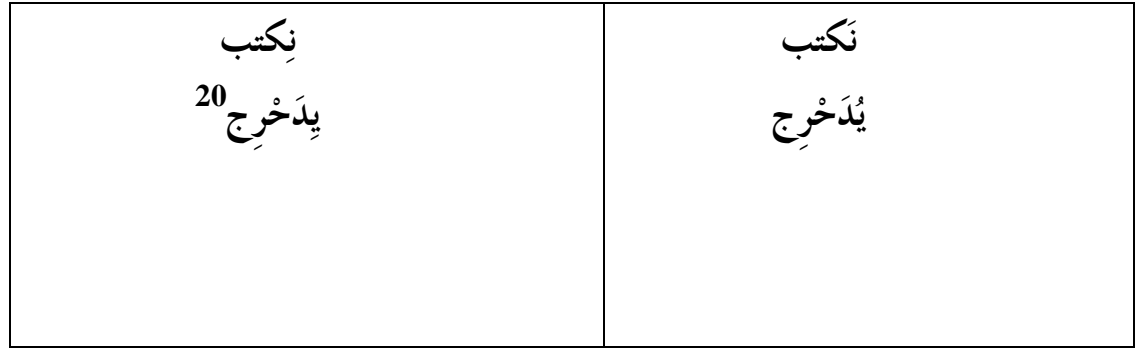

\section{c. Fi'l Amr}

\begin{tabular}{|c|c|}
\hline Dialek Tamim & Dialek Non-Tamim \\
\hline سَانْ & \\
& \\
\hline
\end{tabular}

d. Al Asma' 21

a) Mutsanna

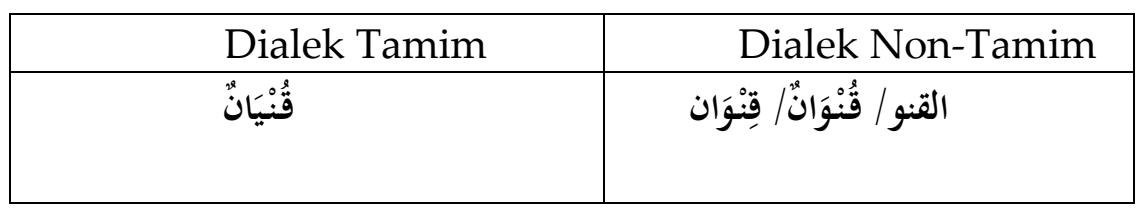

b) 'Adad

\begin{tabular}{|c|c|}
\hline Dialek Tamim & Dialek Non-Tamim \\
\hline 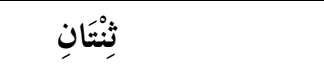 & انْنَتًَانِ \\
\hline خَمْسَةََ عَشْر & خَمْسَنَة عَشَرَ \\
\hline
\end{tabular}

c) Dhamir

\begin{tabular}{|c|c|}
\hline Dialek Tamim & Dialek Non-Tamim \\
\hline di waqof أَنَا di & di waqof أَنَا di \\
\hline أَنَا di wahsol & أَنَ di washol \\
\hline هُ & هو \\
\hline هِيْ & هي \\
\hline أَبَُوُْشِ & 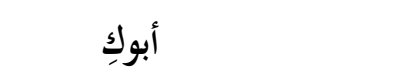 \\
\hline هؤُلاء & هؤلاءٍ \\
\hline
\end{tabular}

${ }^{20}$ Daud Salum, Dirasah al Lahjat al Arabiyyah al Qadimah. (Beirut: Alam al Kutub, 1406/1986). Hal. 64-65.

${ }^{21}$ Lihat Daud Salum, Dirasah al Lahjat al Arabiyyah al Qadimah. (Beirut: Alam al Kutub, 1406/1986). Hal. 33-62.

El-Ibtikar Vol 7 No 1 Juni 2018, 109-121 


\begin{tabular}{|c|c|}
\hline هَهِنَّا / هَهِنَا & هَهُنَا \\
\hline ذَاكَ & ذلك \\
\hline تِيْكَ & تلك \\
\hline ذَانّ & ذَاِِ \\
\hline أولاك & أولالك \\
\hline
\end{tabular}

d) Jama' mudzakkar salim

\begin{tabular}{|l|c|}
\hline Dialek Tamim & Dialek Non-Tamim \\
\hline السنين السنون & dlummah \\
السنين kasroh & fathah \\
\hline
\end{tabular}

e) Asma' al Af'al

\begin{tabular}{|c|c|}
\hline Dialek Tamim & Dialek Non-Tamim \\
\hline أُأََّْ & أُفِقِ \\
\hline هَلََّْ / هَلُمِّم & هَلُمَّ \\
\hline هَيْهَهاتَ & أَيْهَاتَتَ \\
\hline
\end{tabular}

f) Zharf

\begin{tabular}{|c|c|}
\hline Dialek Tamim & Dialek Non-Tamim \\
\hline أَمْسَ / أَمْسُ & أَ أَمْسِ \\
\hline حُوْثُ & حَيْثُ \\
\hline مُذُ / مُذْ & مُذذْ مُ \\
\hline
\end{tabular}

g) Ististna

\begin{tabular}{|c|c|}
\hline Dialek Tamim & Dialek Non-Tamim \\
\hline ليس الطيب إلا المسكُ & ليس الكيب إلا المسكَ \\
\hline ما جاءنى أحد غيرُك & ما جاءنى أحد غيرَك \\
\hline
\end{tabular}

h) Tashghir

\begin{tabular}{|c|c|}
\hline Dialek Tamim & Dialek Non-Tamim \\
\hline أُسَيِّدِ & \\
& \\
\hline
\end{tabular}


i) Qasam

\begin{tabular}{|c|c|}
\hline Dialek Tamim & Dialek Non-Tamim \\
\hline 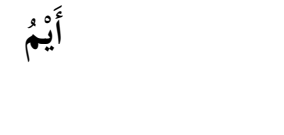 & 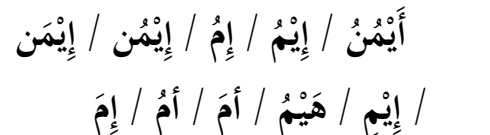 \\
\hline
\end{tabular}

e. Huruf musyabbahah bi fi'l

\begin{tabular}{|c|c|}
\hline Dialek Tamim & Dialek Non-Tamim \\
\hline$ع َ$ & عَنَّ \\
\hline
\end{tabular}

f. Perubahan huruf

\begin{tabular}{|c|c|}
\hline Dialek Tamim & Dialek Non-Tamim \\
\hline ث ث (تلمثت) & ل \\
\hline ص (الصويق، الصوق، الصاق) & س (السوق، الساق، السويق) \\
\hline أ (الأجيل، اتخذت، ، أكّدت). آ & و (الوجيل، وخذت، وكدت). \\
\hline (آكف، آصدت) & أو (أوكف، أوصدت، ) \\
\hline و و (حوث) & ي (حيث) \\
\hline ر ر (رعنَّك) & ل ل (لعلّك \\
\hline ج (أزجم) & ي (أزيم) \\
\hline ش (إشاءه) & ج (إجاءه) \\
\hline ظ (فاظت) & ض (فاضت) \\
\hline س (سراط، بسطة، سقيل، سرقت، & ص (صراط، بصطة، صقيل، \\
\hline مسبغة، سخر، مسدغة) & صرقت، مصغبة، صخر ، مصدغة) \\
\hline كُ (النُكَّة) & ق (النقة) \\
\hline ا 1 (القار) & ي (القير) \\
\hline ق (قشط) & ك (كشط) \\
\hline ص (لصق) & ز (لزق) \\
\hline
\end{tabular}

g. Penambahan huruf

Dialek Tamim

Dialek Non-Tamim 


\begin{tabular}{|c|c|}
\hline مديون & مدين \\
\hline مكول & زناء \\
\hline
\end{tabular}

\section{h. Perubahan Harokat}

a) Ism Masdar

\begin{tabular}{|c|c|}
\hline Dialek Tamim & Dialek Non-Tamim \\
\hline كِسْرة & كَسْرة \\
\hline كِسَر & كِسِ \\
\hline ال العَنُقْ & العُعُق \\
\hline 22 & ضُعْف \\
\hline حَرْم & 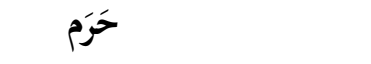 \\
\hline فَخِذ & فَخْذ \\
\hline مَرْض & مَرَض \\
\hline الكِلْمة 23 & الكِلمِة \\
\hline
\end{tabular}

b) Ism Fa'il ala wazn Fa'il

\begin{tabular}{|c|c|}
\hline Dialek Tamim & Dialek Non-Tamim \\
\hline بهيمة & بَبِيمة \\
\hline كِبير & كَبِيْر \\
\hline كِثير & كَثير \\
\hline خِلِيْلِ & خَلِيل \\
\hline شِعِير & شَعير \\
\hline بِخِيل & بَخِيل \\
\hline لِيِيم & لَِيَم \\
\hline شِّهيد 24 & شَهِيد \\
\hline
\end{tabular}

${ }^{22}$ Daud Salum, Dirasah al Lahjat al Arabiyyah al Qadimah. (Beirut: Alam al Kutub, 1406/1986). Hal. 145.

${ }^{23}$ Abd al Ghaffar Hamid Hilal, Al Lahjat al Arabiyyah; Nasyatan wa Tathawwuran. (Kairo: Maktabah Wahbah, 1414/1993). Hal. 300-303. 


\section{i. Hari}

\begin{tabular}{|c|c|}
\hline Dialek Tamim & Dialek Non-Tamim \\
\hline الجُجَمَعَة & الجُمُعَة / الجُمْعة \\
\hline
\end{tabular}

Bertolak dari contoh-contoh di atas, maka dialek Tamim memiliki perbedaan dan karakteristik tersendiri, meskipun ada beberapa kesamaan dialek dalam kata-kata tertentu dengan dialek-dialek lainnya, dengan dialek-dialek lain baik dalam tataran fonem (shawt) yang meliputi bacaan Imalah, dhummah, kasroh, tafkhim dan penggunaan bunyi keras dan jelas; morfem (sharf) dan sintaksis (nahwu) yang meliputi kata kerja, kata sambung, bilangan, dan isim isyarah; maupun semantik (dilalah) seperti kata-kata berikut ini:

\begin{tabular}{|c|c|}
\hline Dialek Tamim & Artinya \\
\hline الحسدي & النسيان \\
الظلمة & $\mathbf{2 5}$ \\
\hline الشعر & السدفة \\
\hline
\end{tabular}

Contoh-contoh dialek di atas tidak mesti monopoli dialek Tamim, karena ia juga memiliki kesamaan dialek dengan dialek-dialek "tetangganya" dan atau dialek-dialek tersebut yang mengikuti dialek Tamim $^{26}$ ataupun sebaliknya pada kata-kata tertentu, antara lain:

\begin{tabular}{|c|c|}
\hline Kata & Dialek \\
\hline أمليت & قيس \\
أمل نجد & نجد \\
\hline أهديته & نجنه \\
\hline
\end{tabular}

${ }^{24}$ Abd al Ghaffar Hamid Hilal, Al Lahjat al Arabiyyah; Nasyatan wa Tathawwuran. (Kairo: Maktabah Wahbah, 1414/1993). Hal. 295-296.

25 Menurut Qais bukan berarti al Dzulmah (kegelapan) melainkan al Dhau (cahaya). Abd al Ghaffar Hamid Hilal, Al Lahjat al Arabiyyah; Nasyatan wa Tathawwuran. (Kairo: Maktabah Wahbah, 1414/1993). Hal. 34.

${ }^{26}$ Daud Salum, Dirasah al Lahjat al Arabiyyah al Qadimah. (Beirut: Alam al Kutub, 1406/1986). Hal. 23. 


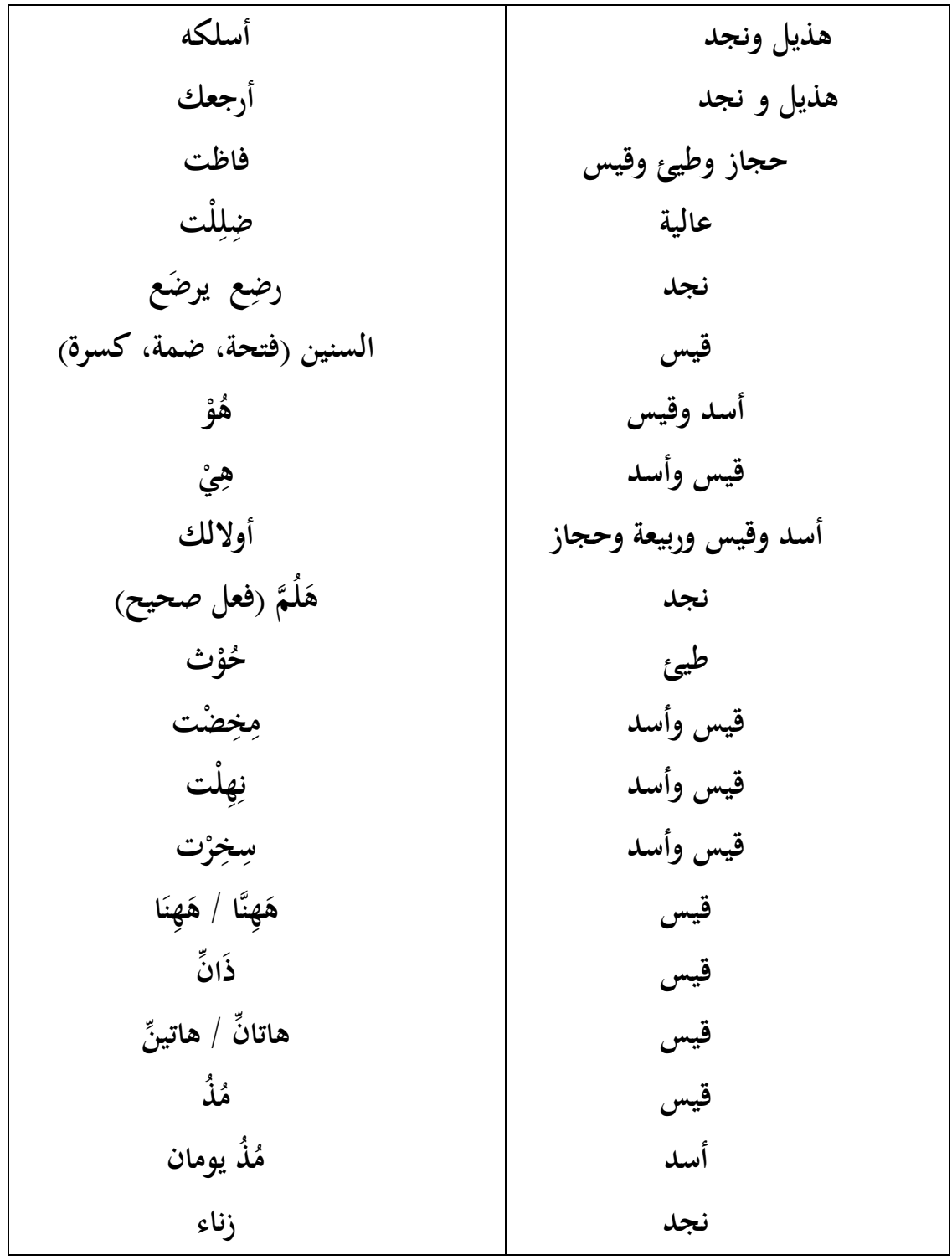

\section{Kesimpulan}

Kemapanan dialek Tamim, setidaknya, sejalan dengan pertumbuhan dialek-dialek yang ada yakni, secara sosiologis dan geografis. Secara sosiologis, dialek Tamim tidak dapat tidak bercampur dengan dialek-dialek tetangganya yang menyebabkan saling pengaruh dan mempengaruhi diantara mereka. Secara geografis, dialek Tamim memiliki tempat dimana ia tinggal dan berkembang, apalagi qabilah Tamim juga sering melakukan hijrah dalam mempertahankan hidupnya sehingga memperluas wilayah yang disinggahinya. 


\section{DAFTAR PUSTAKA}

Ahmad bin Ali, Abu al Abbas. 1982. Fuqlaid al Juman fi Ta'rif bi qabail Arab al Zaman. (Kairo: Dar al Kutub al Islamiyyah).

Al 'Asqalani, Ibn Hajar. Fath al Bari, ix: 9.

Al Jundi, Anwar Muqaddimat al 'Ulum wa al Manahij; Muhawalah libina' $i$ Manhajin Islamiyyin Mutakamil. (Kairo: Dar al Anshar).

Al Nadiri, Muhammad As'ad. 2005. Figh al Lughah wa Masailuhu. (Beirut: al Maktabah al Ashriyah).

Anis, Ibrahim. 1973. Fi al Lahjat al Arabiyyah. (Kairo: Maktabah al Anjalu al Mishriyyah).

Ayyub, Abd al Rahman. Al Arabiyyah wa Lahjatuha. (Kairo: Maktabah Syabab).

Hilal, Abd al Ghaffar Hamid. 1414/1993. Al Lahjat al Arabiyyah; Nasyatan wa Tathawwuran. (Kairo: Maktabah Wahbah).

Salum, Daud. 1406/1986. Dirasah al Lahjat al Arabiyyah al Qadimah. (Beirut: Alam al Kutub).

Syahin, Abd al Shabur. 1996. Fi Ilm Lughah al 'Am. (Beirut: Muassasah al Risalah).

Ya'qub, Amil Badi'. Figh al Lughah al Arabiyyah wa Khashaishuha. (Beirut: Dar al Tsaqafah al Islamiyyah). 